\title{
Mammographic Density Change and Risk of Breast Cancer
}

\author{
Shadi Azam (10 *, Mikael Eriksson*, Arvid Sjölander, Roxanna Hellgren (1) , \\ Marike Gabrielson (1) , Kamila Czene, Per Hall (1)
}

See the Notes section for the full list of authors' affiliations

*Authors contributed equally to this work.

Correspondence to: Shadi Azam, Department of Medical Epidemiology and Biostatistics, Karolinska Institutet, Nobels väg 12 A, 17165 Stockholm, Sweden (e-mail: shadi.azam@ki.se).

\begin{abstract}
Background: We examined the association between annual mammographic density change (MDC) and breast cancer (BC) risk, and how annual MDC influences the association between baseline mammographic density (MD) and BC risk.

Methods: We used the Karolinska Mammography Project for Risk Prediction of Breast Cancer cohort of Swedish women $(\mathrm{N}=43810)$ aged $30-79$ years with full access to $\mathrm{BC}$ risk factors and mammograms. MD was measured as dense area ( $\left.\mathrm{cm}^{2}\right)$ and percent MD using the STRATUS method. We used the contralateral mammogram for women with BC and randomly selected a mammogram from either left or right breast for healthy women. We calculated relative area MDC between repeated examinations. Relative area MDC was categorized as decreased ( $>10 \%$ decrease per year), stable (no change), or increased ( $>10 \%$ increase per year). We used Cox proportional hazards regression to estimate the association of BC with MDC and interaction analysis to investigate how MDC modified the association between baseline MD and BC risk. All tests of statistical significance were two-sided.

Results: In all, 563 women were diagnosed with BC. Compared with women with a decreased MD over time, no statistically significant difference in BC risk was seen for women with either stable MD or increasing MD (hazard ratio $=1.01,95 \%$ confidence interval $=0.82$ to $1.23, P=.90$; and hazard ratio $=0.98,95 \%$ confidence interval $=0.80$ to $1.22, P=.90$, respectively) . Categorizing baseline MD and subsequently adding MDC did not seem to influence the association between baseline MD and BC risk.

Conclusions: Our results suggest that annual MDC does not influence BC risk. Furthermore, MDC does not seem to influence the association between baseline $\mathrm{MD}$ and $\mathrm{BC}$ risk.
\end{abstract}

Mammographic density (MD) is a strong risk factor for breast cancer $(B C)(1,2)$. The dense part of the breast consists of epithelial tissue and stroma and appears bright on a mammogram, whereas fat tissue appears dark (3). Women with mammograms where the dense tissue occupies more than $75 \%$ of a mammogram have a 4-6 times greater risk of BC compared with women with dense tissue occupying less than $5 \%(1,4)$. Most studies on the association of MD and BC risk have involved only a single measure of density with a large variation in time between BC and time of last negative mammogram $(1,5)$. However, MD is a dynamic trait that typically declines with increasing age (6), a physiological phenomenon called involution $(7,8)$. We have previously shown, on average, MD decreases by $1 \mathrm{~cm}^{2} / \mathrm{y}$ (9). An apparent paradox is that MD decreases with age in most women whereas BC incidence increases. One explanation could be that MD change (MDC), rather than a MD measure at a single point in time, is a better measure of BC risk. Our hypothesis was that women who do not experience a density decrease over time have a higher risk of BC compared with women in whom a decrease is seen.

A few studies have evaluated the association between MDC and $\mathrm{BC}$ risk. However, the results are conflicting, and all previous studies have important limitations such as inability to investigate MDC and risk of BC among premenopausal women, 
because screening in most countries starts at the age of 50 years (10-12); using retrospective case-control sampling, which is more susceptible to bias than the prospective cohort design (1013); using an obsolete imaging technique (screen-film mammography instead of full-field digital mammography) (10); using a semi-automated, reader-dependent measure of density (11, 14); not aligning images before density measures are performed (15); and using a qualitative and crude measurement of MD (Breast Imaging Reporting and Data System [BI-RADS] score) (14).

In the current study, we were able to address all of these limitations. We investigated 43810 women from the unique prospective Karolinska Mammography Project for Risk Prediction of Breast Cancer (KARMA) cohort (16), and used a novel approach when measuring density changes over time, to elucidate the association between MDC with age and risk of BC separated by menopausal status. Furthermore, we investigated if adding MDC to a single baseline measure of MD may be a better method to predict a woman's risk of $\mathrm{BC}$ than using a baseline measure alone.

\section{Methods}

\section{Study Population}

KARMA is a population-based prospective screening cohort (16). All women invited for screening from January 2011 to March 2013 at four mammography units in the national mammography screening program in Sweden were invited to participate in the study. Women with a baseline mammogram $(n=70874)$ were included in this study. Informed consent was given for a continuous collection of mammograms. Reasons for exclusion are given in Figure 1, and the final analyses included 43810 women aged 30-79years. All participants signed an informed consent, and the ethical review board at Karolinska Institute approved the study.

\section{Measurement}

Processed mammograms from the mediolateral oblique view of left and right breasts were collected from full-field digital mammography systems. For women with $\mathrm{BC}$, we used the mammograms from the contralateral breast (ie, the breast not having a tumor) and for women without BC, we randomly selected mammograms from either left or right breast and followed MD of the same breast to the end of follow-up. Dense area $\left(\mathrm{cm}^{2}\right)$ and percent MD were measured using the STRATUS method (15). We chose to present the results mainly using MD area because, in contrast to percent MD, it is less influenced by body mass index (BMI) (17). Nevertheless, for compatibility with other studies, we also presented results using percent MD. We chose to categorize women according to baseline MD area and percent MD in quartile; however, we combined the two highest categories due to few women in the highest quartile. An alternative would have been to use BIRADS categories A-D (18), but the distribution of women according to that score makes subgroup analyses unstable.

STRATUS is a fully automated tool developed to analyze digital and analogue images using an algorithm that measures density on all types of images regardless of vendor. STRATUS uses threshold techniques and assesses image features from the mammograms and estimates MD using machine learning. STRATUS measures the MD density area and the breast area and calculates the percent density from these measures (15). In using the repeated mammograms from the same woman, it is important to take technical differences between mammograms into consideration. Supplementary Figure 1 (available online) illustrates how the breast tissue from the same woman is presented in a mammogram at two points in time. Frame A (Supplementary Figure 1, available online) shows that the same amount of tissue is not found in two mammograms of the same breast taken within minutes, which gives a false difference when comparing density. To minimize the effect of this artifact, mammograms were aligned before MD measurements (Frame B). The concept of alignment and the method has been described previously (15). In the current study, mammograms from the same woman were aligned before density measures were performed.

\section{Covariates}

At baseline, participants who completed an extensive webbased questionnaire covering established risk factors associated with BC mammograms taken within \pm 3 months from the date of answering the questionnaires were considered baseline mammograms. Risk factors were categorized as: age at baseline $\left(<50,50-60,>60\right.$ years), BMI $\left(<20,20-24.9,25-29.9, \geq 30 \mathrm{~kg} / \mathrm{m}^{2}\right)$, smoking status (never, former, current), alcohol consumption $(0,0.1-10,>10 \mathrm{~g} / \mathrm{d})$, physical activity $(<40,40-44.9,45.0-49.9, \geq 50$ metabolic equivalent of task-h/d), age at first birth $(<24.9,25-$ $29.9, \geq 30$ years), number of children $(0,1-2, \geq 3)$, breast feeding duration $(<6,6-12,>12$ months), time since last birth $(<10$, $\geq 10$ years), age at menarche ( $<13, \geq 13$ years), oral contraceptive use (never, ever), menopausal hormone therapy (MHT) status (never, former, current), family history of BC (yes, no), MD area $\left(<9,9-20,>20 \mathrm{~cm}^{2}\right)$, and percent MD $(<5,5-25,>25 \%)$ at baseline. Women reporting no natural menstruation over the past 12 months before study entry or no menstruation due to oophorectomy were considered postmenopausal. Women with missing information on menstruation status or having no menstruation due to gynecological surgeries other than oophorectomy were considered premenopausal if they were age 50 years or younger and postmenopausal if older than 50 years.

\section{Statistical Analyses}

Cox proportional hazards regression was used, with age as the underlying time scale, to estimate the association between established risk factors for $\mathrm{BC}$ and $\mathrm{BC}$ risk. Hazard ratios (HRs) and $95 \%$ confidence intervals (CIs) were reported. The proportional-hazards assumption was tested using the Schoenfeld residual test, and no major model violation was observed. All associations were adjusted for age and BMI at baseline.

To investigate the association between area MDC and risk of BC, we carried out analyses in two steps. First, for each woman and consecutive examinations, we calculated the relative area MDC per year between each of the consecutive examinations. Specifically, for two consecutive examinations at time points (ie, ages) t1 and t2, with measured areas MDC, MD1, and MD2, respectively, we defined the relative MDC per year as (MD2 $\mathrm{MD} 1) / \mathrm{MD} 1 /(\mathrm{t} 2$ - $\mathrm{t} 1)$. This relative (to MD1) measure reflects the notion that a decrease with, for example, $10 \mathrm{~cm}^{2}$ from MD1 $=50$ $\mathrm{cm}^{2}$ is biologically more "dramatic" than a decrease with $10 \mathrm{~cm}^{2}$ from $\mathrm{MD} 1=100 \mathrm{~cm}^{2}$. Relative area MDC was categorized as decrease ( $>10 \%$ decrease per year), stable (no change), and increase ( $>10 \%$ increase per year) in agreement with previous literature $(19,20)$. Second, we used Cox proportional hazard 


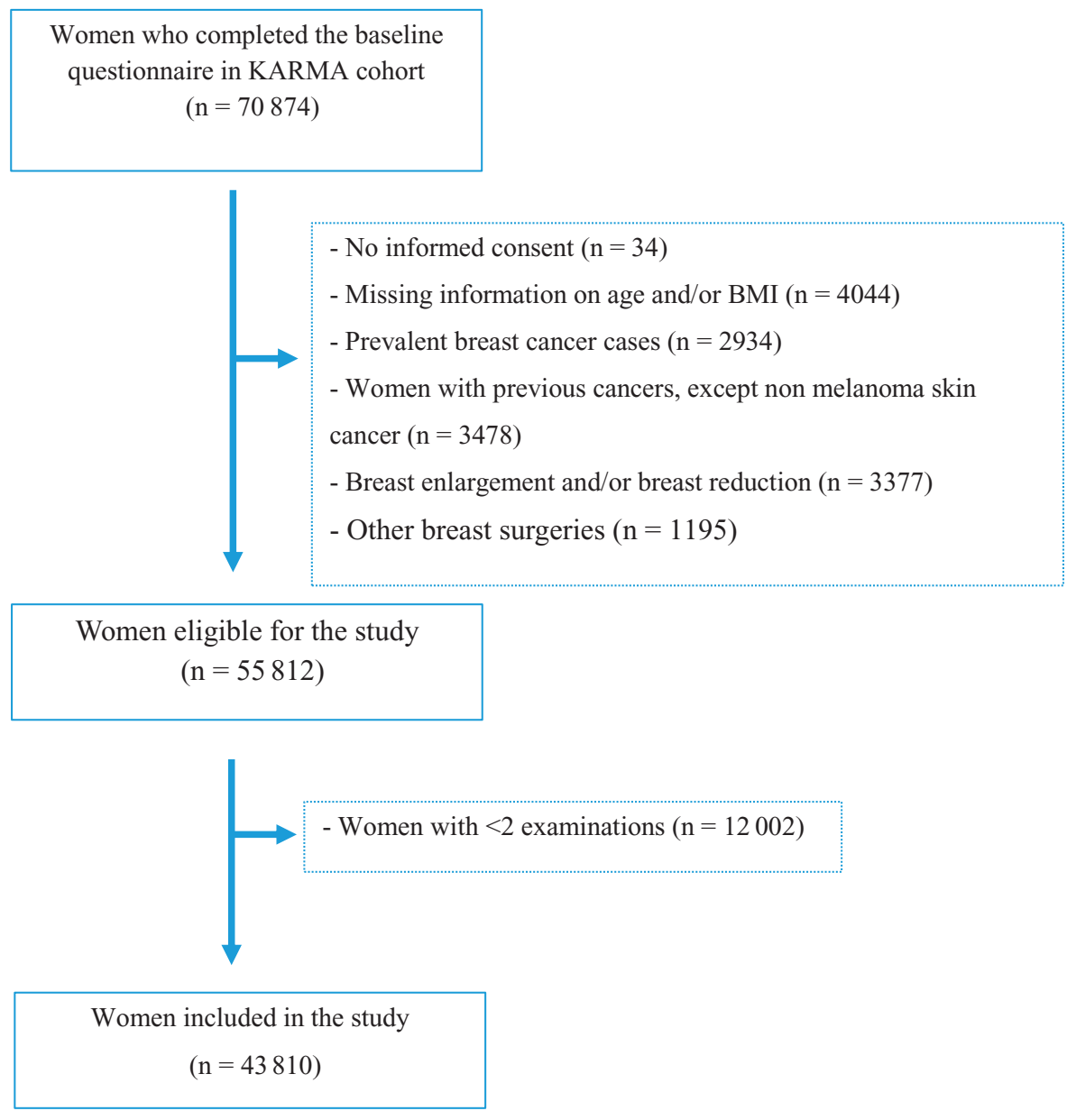

Figure 1. Reasons for exclusion of participants in the Karolinska Mammography Project for Risk Prediction of Breast Cancer (KARMA) cohort. BMI = body mass index.

regression to estimate the association of $\mathrm{BC}$ with relative area MDC, treating relative MDC as a time-varying exposure in the model. The proportional-hazards assumption was tested using the Schoenfeld residual test, and no major model violation was observed. The associations were adjusted for age, BMI, and dense area $\left(\mathrm{cm}^{2}\right)$ at baseline, assuming only main effects of (eg, no interactions between) these covariates and relative MDC. Finally, we repeated the analyses, allowing for interactions between relative MDC and baseline MD, to study how these jointly influence the $\mathrm{BC}$ risk, and a global test was used to determine the presence of interactions. The same analyses were performed using percent density.

Finally, the Pearson correlation coefficient was used to assess the association between baseline MD area and baseline percent MD with baseline BMI. All statistical analyses were performed with $\mathrm{R}$ version 3.4.1. $\mathrm{P}$ values, obtained from two-sided Wald/maximum likelihood ratio tests, of less than .05 were considered statistically significant.

\section{Results}

\section{Baseline Characteristics}

Baseline characteristics are given in Table 1 for all 43810 women separated by BC status. The mean (SD) number of years between first and last mammogram was $5.4(0.6)$ years. The time interval between mammography rounds in this cohort was
18-24 months. The majority of women (77.6\%) had completed three or more rounds of mammography, and the maximum number of the mammography rounds was five in this cohort.

A total of 563 women were diagnosed with BC during followup. Women with BC were older, more likely to be smokers and alcohol drinkers, and less likely to have a child before the age of 25 years compared with women without BC (Table 1). However, the proportions of nulliparous women were more or less the same in women with and without BC $(13.3 \%$ and $14.1 \%$, respectively). Both groups of women tended to breastfeed longer than a year. Finally, women with BC were more likely to have a firstdegree relative diagnosed with BC (22.2\%) compared with women without BC (13.3\%) (Table 1).

\section{Covariates and Risk of Breast Cancer}

Premenopausal women with high BMI $\left(\geq 30 \mathrm{~kg} / \mathrm{m}^{2}\right)$ had statistically significantly lower risk of $\mathrm{BC}(\mathrm{HR}=0.47,95 \% \mathrm{CI}=0.24$ to 0.92$) \mathrm{com}$ pared with premenopausal women with low BMI $\left(<20 \mathrm{~kg} / \mathrm{m}^{2}\right)$ (Table 2). No association between BMI and BC was seen for postmenopausal women, but the $P$ value was statistically significant when considering BMI as a continuous variable $(P=.002)$. A statistically significant greater risk of $\mathrm{BC}$ was seen in older women, women having their first child later in life, postmenopausal women using $\mathrm{MHT}$, and women with a first-degree relative with BC (Table 2). 
Table 1. Baseline characteristics for the 43810 women included in the study separated by BC status*

\begin{tabular}{|c|c|c|c|}
\hline \multirow[b]{2}{*}{ Characteristic } & \multirow[b]{2}{*}{ Total No. (\%) } & \multicolumn{2}{|c|}{ Breast cancer, No. (\%) } \\
\hline & & No & Yes \\
\hline No. of women & 43810 & 43247 & 563 \\
\hline \multicolumn{4}{|l|}{ No. of screening examinations } \\
\hline 2 rounds & $10014(22.8)$ & $9675(22.3)$ & $339(60.2)$ \\
\hline$\geq 3$ rounds & $33796(77.1)$ & $33572(77.6)$ & $224(39.7)$ \\
\hline Age at baseline, mean (SD), y & $53.7(9.4)$ & $53.6(9.4)$ & $57.3(9.4)$ \\
\hline \multicolumn{4}{|l|}{ Menopausal status } \\
\hline Pre & $20718(47.2)$ & $20518(47.4)$ & $200(35.5)$ \\
\hline Post & $23092(52.7)$ & 22729 (52.55) & $363(64.4)$ \\
\hline BMI, mean (SD), $\mathrm{kg} / \mathrm{m}^{2}$ & $25.1(4.1)$ & $25.1(4.1)$ & $25.5(4.1)$ \\
\hline \multicolumn{4}{|l|}{$\mathrm{BMI}, \mathrm{kg} / \mathrm{m}^{2}$} \\
\hline$<20$ & $2382(5.4)$ & $2347(5.4)$ & $35(6.2)$ \\
\hline $20-24.9$ & $22298(50.8)$ & $22045(50.9)$ & $253(44.9)$ \\
\hline $25-29.9$ & $13805(31.5)$ & $13603(31.4)$ & $202(35.8)$ \\
\hline$\geq 30$ & $5325(12.1)$ & $5252(12.1)$ & 73 (12.9) \\
\hline \multicolumn{4}{|l|}{ Smoking status } \\
\hline Never & $21074(48.1)$ & $20826(48.1)$ & $248(44.0)$ \\
\hline Former & $17234(39.3)$ & $16990(39.2)$ & $244(43.3)$ \\
\hline Current & $5128(11.7)$ & $5060(11.7)$ & $68(12.0)$ \\
\hline Missing & $374(0.8)$ & $371(0.8)$ & $3(0.5)$ \\
\hline Alcohol consumption, g/d, mean (SD), g/d & $7.1(8.5)$ & $7.1(8.5)$ & $7.4(8.2)$ \\
\hline \multicolumn{4}{|l|}{ Alcohol consumption, g/d } \\
\hline 0 & $7957(18.1)$ & $7861(18.1)$ & $96(17.0)$ \\
\hline $0.1-10$ & $26935(61.4)$ & $26584(61.4)$ & $351(62.3)$ \\
\hline$>10$ & $8192(18.6)$ & $8084(18.6)$ & $108(19.1)$ \\
\hline Missing & $726(1.6)$ & $718(1.6)$ & $8(1.4)$ \\
\hline Physical activity, MET-h/d, mean (SD), MET-h/d & $42.5(6.2)$ & $42.5(6.2)$ & $41.9(5.6)$ \\
\hline \multicolumn{4}{|l|}{ Physical activity, MET-h/d } \\
\hline$<40$ & $15263(34.8)$ & $15068(34.8)$ & $195(34.6)$ \\
\hline $40.0-44.9$ & $15245(34.7)$ & $15032(34.7)$ & $213(37.8)$ \\
\hline $45.0-49.9$ & 7769 (17.7) & $7667(17.7)$ & $102(18.1)$ \\
\hline$\geq 50.0$ & $4305(9.8)$ & $4268(9.8)$ & $37(6.5)$ \\
\hline Missing & $1228(2.8)$ & $1212(2.8)$ & $16(2.8)$ \\
\hline Age at first birth, mean (SD), y & $27.3(5.2)$ & $27.3(5.2)$ & $27.0(5.0)$ \\
\hline \multicolumn{4}{|l|}{ Age at first birth, y } \\
\hline$<25$ & $12081(27.5)$ & $11931(27.5)$ & $150(26.6)$ \\
\hline $25-29.9$ & $13547(30.9)$ & $13363(30.8)$ & $184(32.6)$ \\
\hline$\geq 30$ & $12348(28.1)$ & $12198(28.2)$ & $150(26.6)$ \\
\hline Missing & 5834 (13.3) & $5755(13.3)$ & $79(14.0)$ \\
\hline No. of births, mean (SD) & $1.9(1.0)$ & $1.9(1.0)$ & $1.8(1.0)$ \\
\hline \multicolumn{4}{|l|}{ No. of births } \\
\hline 0 & $5416(12.3)$ & $6101(14.1)$ & 75 (13.3) \\
\hline $1-2$ & $27249(62.1)$ & $20792(48.0)$ & $356(63.2)$ \\
\hline$\geq 3$ & $10743(24.5)$ & $8582(19.8)$ & $128(22.7)$ \\
\hline Missing & $402(1.0)$ & $398(0.9)$ & $4(0.7)$ \\
\hline Breast-feeding duration, mean (SD), mo & $18.8(10.0)$ & $18.9(10.0)$ & $17.4(9.4)$ \\
\hline \multicolumn{4}{|l|}{ Duration of breast-feeding, mo } \\
\hline$<6$ & $1780(4.0)$ & $1748(4.0)$ & $32(5.6)$ \\
\hline $6-12$ & $5201(11.8)$ & $5121(11.8)$ & $80(14.2)$ \\
\hline$>12$ & $28218(64.4)$ & $27873(64.4)$ & $345(61.2)$ \\
\hline Missing & $2510(5.7)$ & $2485(5.7)$ & $25(4.4)$ \\
\hline Time since last birth, mean (SD), y & $22.0(11.8)$ & $21.9(11.8)$ & $26.3(11.8)$ \\
\hline \multicolumn{4}{|l|}{ Time since last birth, y } \\
\hline$<10$ & $6751(15.4)$ & $6703(15.4)$ & $48(8.5)$ \\
\hline$\geq 10$ & 31531 (71.9) & $31093(71.8)$ & $438(77.7)$ \\
\hline Missing & $5528(12.6)$ & $5451(12.6)$ & 77 (13.6) \\
\hline Age at menarche, mean (SD), y & $13.0(1.4)$ & $13.0(1.4)$ & $13.1(1.4)$ \\
\hline \multicolumn{4}{|l|}{ Age at menarche, $\mathrm{y}$} \\
\hline$<13$ & $14840(33.8)$ & $14666(33.9)$ & $174(30.9)$ \\
\hline$\geq 13$ & $27842(63.5)$ & $27470(63.5)$ & $372(66.0)$ \\
\hline Missing & $1128(2.5)$ & $1111(1.4)$ & $17(3.0)$ \\
\hline
\end{tabular}


Table 1. (continued)

\begin{tabular}{|c|c|c|c|}
\hline \multirow[b]{2}{*}{ Characteristic } & \multirow[b]{2}{*}{ Total No. (\%) } & \multicolumn{2}{|c|}{ Breast cancer, No. (\%) } \\
\hline & & No & Yes \\
\hline \multicolumn{4}{|c|}{ Contraceptive use } \\
\hline Never & $5923(13.5)$ & 5824 (13.4) & $99(17.5)$ \\
\hline Ever & $37055(84.5)$ & $36598(84.6)$ & $457(81.1)$ \\
\hline Missing & $832(1.8)$ & 825 (1.9) & $7(1.2)$ \\
\hline \multicolumn{4}{|l|}{ MHT } \\
\hline Never user & 33390 (76.2) & $32999(76.3)$ & $391(69.4)$ \\
\hline Former user & $5734(13.0)$ & $5638(13.0)$ & $96(17.0)$ \\
\hline Current user & $1483(3.3)$ & $1448(3.3)$ & $35(6.2)$ \\
\hline Missing & $3203(7.3)$ & $3162(7.3)$ & $41(7.2)$ \\
\hline \multicolumn{4}{|c|}{ Family history of BC } \\
\hline No & 36755 (83.8) & $36332(84.0)$ & $423(75.1)$ \\
\hline Yes & $5883(13.4)$ & $5758(13.3)$ & $125(22.2)$ \\
\hline Missing & $1172(2.6)$ & $1157(2.6)$ & $15(2.6)$ \\
\hline
\end{tabular}

${ }^{*} \mathrm{BC}=$ breast cancer; $\mathrm{BMI}=$ body mass index; $\mathrm{MET}=$ metabolic equivalent of task; $\mathrm{MHT}=$ menopausal hormone therapy.

\section{Relative MD Change and Risk of BC}

The risk of $\mathrm{BC}$ was more or less the same among women with stable $\mathrm{MD}$ ( $\mathrm{HR}=1.01,95 \% \mathrm{CI}=0.82$ to $1.23, \mathrm{P}=.90)$ and women with more than a $10 \%$ annual increase in $\mathrm{MD}(\mathrm{HR}=0.98,95 \% \mathrm{CI}$ $=0.80$ to $1.22, P=.90$ ) compared with women with an annual decrease greater than $10 \%$ in $\mathrm{MD}$ (Table 3 ). The same results were seen among postmenopausal women. Among premenopausal women, there was a weak but statistically nonsignificant association between annual increase in MD greater than 10\% and risk of $\mathrm{BC}(\mathrm{HR}=1.12,95 \% \mathrm{CI}=0.77$ to $1.64, P=.53)$ compared with premenopausal women with an annual decrease in MD greater than $10 \%$ (Table 3). Similar results were found using percent MD (Supplementary Table 1, available online).

Only for women aged 40-49 years did we see a tendency of a difference in risk related to MDC. Women with an increase in annual MD greater than $10 \%$ had a statistically nonsignificant $30 \%$ higher risk compared to perimenopausal women with greater than 10\% annual MD reduction (Supplementary Table 2, available online).

Table 4 shows the joint effect of baseline MD and relative area MDC on BC risk separated by menopausal status. Women in the lowest category of baseline MD with a decrease in density over time were used as the reference. There was a two to three times higher risk of BC when contrasting the lowest and highest baseline MD among all women, regardless of MDC (Table 4). Among premenopausal women, there was a fourfold higher risk when comparing women at high and low baseline MD, and no difference in risk was seen when comparing the lowest and highest baseline MD in women who did and did not experience a density decrease. Among postmenopausal regardless of MDC, women with high baseline MD $\left(>20 \mathrm{~cm}^{2}\right)$ had two times higher risk of BC than postmenopausal women with low baseline $\mathrm{MD}\left(<9 \mathrm{~cm}^{2}\right)$. Similar results were seen when using percent density (Supplementary Table 3, available online).

The correlation between baseline MD area and BMI was $\rho=-0.30$ and the correlation between baseline percent MD and BMI was $\rho=-0.50$. Both MD area and percent MD were negatively correlated with BMI, but the correlation was stronger for percent MD than MD area. Therefore, we chose to use $\mathrm{MD}$ area in the main analyses because it is less influenced by BMI.

\section{Discussion}

Using a large prospective cohort, we found no evidence for an association between annual MDC and risk of BC. Furthermore, MDC did not seem to influence the association between baseline $\mathrm{MD}$ and $\mathrm{BC}$ risk. Our results suggest that risk of $\mathrm{BC}$ is dependent on baseline MD, with no additional value of adding MDC. Our results on association between established risk factors and $\mathrm{BC}$ risk were as expected and in line with previous studies (2125), except that, among postmenopausal women, we did not see an increased risk in women with higher BMI.

The association between a single measure of $\mathrm{MD}$ and $\mathrm{BC}$ risk has been investigated extensively, and we confirmed that high MD at baseline is associated with an increased BC risk $(2,10,14,26)$. In contrast, studies of how MDC over time influences BC risk have been conflicting (10-14). The results from prior studies, which used the contralateral breast for cases, are in agreement with our findings that MDC does not influence the risk of BC (11-13). Maskarinec et al. and Vachon et al. who conducted case-control study designs with sufficient sample sizes and appropriate quantitative MD measurements did not observe any associations between percent MDC and risk of BC $(11,12)$. In agreement, Lokate et al. and van Gils et al. both observed a weak but statistically nonsignificant association between MDC and BC risk $(10,13)$. Finally, in a large prospective cohort of more than 300000 women, Kerlikowske et al. found that women who did not decrease in MD over time had a higher BC risk compared with women who decreased (14). A major limitation of that study was that MD was measured and compared only at two time points using the BIRADS score, which is a qualitative and rather crude measurement of MD. Another limitation of that study was an inability to adjust for BMI due to missing data. We previously showed that BMI is an important determinant of MDC (9). However, in line with our findings, the highest BC risk was observed for women who had the highest MD at first mammogram, regardless of whether MD decreased at the last mammogram (14).

To our knowledge, this is the first large population-based study examining not only the association between annual MDC and risk of $\mathrm{BC}$ but also investigating if adding MDC to a single baseline measure of MD improves BC risk prediction. Strengths of our study are the prospective population-based design, detailed information on the established $\mathrm{BC}$ risk factors, access to 
Table 2. HR of established BC risk factors for all 43810 women

\begin{tabular}{|c|c|c|c|c|}
\hline Determinant & $\begin{array}{c}\text { Non-BC women, } \\
\text { No. (\%) }\end{array}$ & $\begin{array}{l}\text { Women with } \\
\text { BC, No. (\%) }\end{array}$ & $\begin{array}{c}\text { Adjusted model* } \\
\text { HR (95\% CI) }\end{array}$ & $\mathrm{P} \dagger$ \\
\hline Total & $43247(100.0)$ & $563(100.0)$ & & \\
\hline \multicolumn{5}{|l|}{ Age baseline, ył } \\
\hline$<50$ & $16825(38.9)$ & $138(24.5)$ & 1.00 (Referent) & \\
\hline $50-60$ & $13722(31.7)$ & $181(32.1)$ & 1.59 (1.27 to 1.98$)$ & $<.001$ \\
\hline$>60$ & $12700(29.3)$ & $244(43.3)$ & 2.32 (1.88 to 2.85$)$ & $<.001$ \\
\hline Continuous & & & & $<.001$ \\
\hline \multicolumn{5}{|c|}{ Baseline dense area, $\mathrm{cm}^{2}$} \\
\hline$<9$ & $10416(24.0)$ & $105(18.6)$ & 1.00 (Referent) & \\
\hline $9-20$ & $8913(20.6)$ & $124(22.0)$ & 1.66 (1.27 to 2.17$)$ & $<.001$ \\
\hline$>20$ & $23763(54.9)$ & $332(58.9)$ & 2.24 (1.76 to 2.85$)$ & $<.001$ \\
\hline Continuous & & & & $<.001$ \\
\hline \multicolumn{5}{|c|}{ Density at baseline, $\%$} \\
\hline$<5$ & $9329(21.5)$ & $100(17.7)$ & 1.00 (Referent) & \\
\hline $5-25$ & $16626(38.4)$ & 236 (41.9) & 1.74 (1.36 to 2.22$)$ & $<.001$ \\
\hline$>25$ & $17067(39.4)$ & $225(40.0)$ & 2.54 (1.92 to 3.37$)$ & $<.001$ \\
\hline Continuous & & & & $<.001$ \\
\hline \multicolumn{5}{|l|}{ BMI, $\mathrm{kg} / \mathrm{m}^{2} \S$} \\
\hline$<20$ & $2347(5.4)$ & $35(6.2)$ & 1.00 (Referent) & \\
\hline $20-24.9$ & $22045(50.9)$ & $253(44.9)$ & 0.75 (0.53 to 1.07$)$ & .12 \\
\hline $25-29.9$ & $13603(31.4)$ & $202(35.8)$ & 0.91 (0.64 to 1.31$)$ & .64 \\
\hline$\geq 30$ & $5252(12.1)$ & $73(12.9)$ & 0.88 (0.58 to 1.32$)$ & .54 \\
\hline Continuous & & & & .08 \\
\hline \multicolumn{5}{|c|}{ BMI in premenopausal women, $\mathrm{kg} / \mathrm{m}^{2}$} \\
\hline$<20$ & $1267(6.1)$ & $18(9.0)$ & 1.00 (Referent) & \\
\hline $20-24.9$ & $10961(53.4)$ & $100(50.0)$ & 0.61 (0.37 to 1.01$)$ & .05 \\
\hline $25-29.9$ & $5837(28.4)$ & $64(32.0)$ & 0.71 (0.42 to 1.20$)$ & .20 \\
\hline$\geq 30$ & $2453(11.9)$ & $18(9.0)$ & 0.47 (0.24 to 0.92$)$ & .02 \\
\hline Continuous & & & & .27 \\
\hline \multicolumn{5}{|c|}{ BMI in postmenopausal women, $\mathrm{kg} / \mathrm{m}^{2}$} \\
\hline$<20$ & $1080(4.7)$ & $17(4.6)$ & 1.00 (Referent) & \\
\hline $20-24.9$ & $11084(48.7)$ & $153(42.1)$ & 0.90 (0.54 to 1.49$)$ & .69 \\
\hline $25-29.9$ & $7766(34.1)$ & $138(38.0)$ & 1.13 (0.68 to 1.87$)$ & .62 \\
\hline$\geq 30$ & $2799(12.3)$ & $55(15.1)$ & 1.26 (0.73 to 2.17$)$ & .39 \\
\hline Continuous & & & & .002 \\
\hline \multicolumn{5}{|l|}{ Smoking status } \\
\hline Never & $20826(48.1)$ & $248(44.0)$ & 1.00 (Referent) & \\
\hline Former & $16990(39.2)$ & $244(43.3)$ & 1.05 (0.88 to 1.26$)$ & .54 \\
\hline Current & $5060(11.7)$ & $68(12.0)$ & $1.08(0.82$ to 1.41$)$ & .56 \\
\hline \multicolumn{5}{|c|}{ Alcohol consumption, g/d } \\
\hline 0 & 7861 (18.1) & $96(17.0)$ & 1.00 (Referent) & \\
\hline $0.1-10$ & $26584(61.4)$ & $351(62.3)$ & 1.13 (0.90 to 1.42$)$ & .29 \\
\hline$>10$ & $8084(18.6)$ & $108(19.1)$ & 1.05 (0.79 to 1.38$)$ & .72 \\
\hline Continuous & & & & .96 \\
\hline \multicolumn{5}{|c|}{ Physical activity, MET-h/d } \\
\hline$<40$ & $15068(34.8)$ & $195(34.6)$ & 1.00 (Referent) & \\
\hline $40-44.9$ & $15032(37.7)$ & $213(37.8)$ & $1.13(0.93$ to 1.38$)$ & .20 \\
\hline $45.0-49.9$ & 7667 (17.7) & $102(18.1)$ & 1.17 (0.92 to 1.49$)$ & .19 \\
\hline$\geq 50.0$ & $4268(9.8)$ & $37(6.5)$ & 0.79 (0.56 to 1.14$)$ & .21 \\
\hline Continuous & & & & .31 \\
\hline \multicolumn{5}{|c|}{ Age at first birth, $y$} \\
\hline$<25$ & $11931(27.5)$ & $150(26.6)$ & 1.00 (Referent) & \\
\hline $25-29.9$ & $13363(30.8)$ & $184(32.6)$ & $1.26(1.01$ to 1.56$)$ & .03 \\
\hline$\geq 30$ & $12198(28.2)$ & $150(26.6)$ & 1.39 (1.10 to 1.77$)$ & .005 \\
\hline Continuous & & & & .05 \\
\hline \multicolumn{5}{|l|}{ No. of children } \\
\hline 0 & $6101(14.1)$ & $75(13.3)$ & 1.00 (Referent) & \\
\hline $1-2$ & $20792(48.0)$ & $356(63.2)$ & 0.93 (0.72 to 1.19$)$ & .58 \\
\hline$\geq 3$ & $8582(19.8)$ & $128(22.7)$ & 0.82 (0.62 to 1.10$)$ & .19 \\
\hline Continuous & & & & .15 \\
\hline
\end{tabular}


Table 2. (continued)

\begin{tabular}{|c|c|c|c|c|}
\hline Determinant & $\begin{array}{l}\text { Non-BC women, } \\
\text { No. (\%) }\end{array}$ & $\begin{array}{l}\text { Women with } \\
\text { BC, No. (\%) }\end{array}$ & $\begin{array}{l}\text { Adjusted model } \\
\text { HR }(95 \% \text { CI })\end{array}$ & $P \dagger$ \\
\hline \multicolumn{5}{|c|}{ Breast-feeding duration, mo } \\
\hline$<6$ & $1748(4.0)$ & $32(5.6)$ & 1.22 (0.85 to 1.76$)$ & .27 \\
\hline $6-12$ & $5121(11.8)$ & $80(14.2)$ & 1.09 (0.85 to 1.39$)$ & .48 \\
\hline$\geq 12$ & $27873(64.4)$ & $345(61.2)$ & 1.00 (Referent) & \\
\hline Continuous & & & & .13 \\
\hline \multicolumn{5}{|c|}{ Time since last birth, $y$} \\
\hline$<10$ & $6703(15.4)$ & $48(8.5)$ & 1.00 (Referent) & \\
\hline$\geq 10$ & $31093(71.8)$ & $438(77.7)$ & 0.98 (0.66 to 1.46$)$ & .92 \\
\hline Continuous & & & & .98 \\
\hline \multicolumn{5}{|c|}{ Age at menarche, $y$} \\
\hline$<13$ & $14666(33.9)$ & $174(30.9)$ & 1.00 (Referent) & \\
\hline$\geq 13$ & $27470(63.5)$ & $372(66.0)$ & 1.06 (0.88 to 1.27$)$ & .49 \\
\hline Continuous & & & & .77 \\
\hline \multicolumn{5}{|c|}{ Contraceptive use } \\
\hline Never & $5824(13.4)$ & $99(17.5)$ & 1.00 (Referent) & \\
\hline Ever & $36598(84.6)$ & $457(81.1)$ & 0.90 (0.72 to 1.12$)$ & .36 \\
\hline \multicolumn{5}{|l|}{ MHT status $\|$} \\
\hline Never user & $14153(62.2)$ & $204(56.1)$ & 1.00 (Referent) & \\
\hline Former user & $5004(22.0)$ & $92(25.3)$ & 1.01 (0.78 to 1.30$)$ & .92 \\
\hline Current user & $1162(5.1)$ & $32(8.8)$ & 1.86 (1.28 to 2.71$)$ & .001 \\
\hline \multicolumn{5}{|c|}{ Family history of BC } \\
\hline No & $36332(84.0)$ & $423(75.1)$ & 1.00 (Referent) & \\
\hline Yes & $5758(13.3)$ & $125(22.2)$ & 1.76 (1.44 to 2.15$)$ & $<.001$ \\
\hline
\end{tabular}

${ }^{*}$ Adjusted model: age (continuous) and BMI (continuous) at baseline. $\mathrm{BC}=$ breast cancer; $\mathrm{BMI}=$ body mass index; $\mathrm{CI}=$ confidence interval; $\mathrm{HR}=\mathrm{hazard}$ ratio; $\mathrm{MET}=$ metabolic equivalent of task; MHT = menopausal hormone therapy.

$\dagger P$ value from two-sided maximum likelihood ratio test.

$\ddagger$ Not adjusted for age at baseline.

$\S$ Not adjusted for BMI.

$\|$ Among postmenopausal women only.

Table 3. HRs of BC risk in relation to change in MD area separated by menopausal status

\begin{tabular}{|c|c|c|c|c|c|c|}
\hline \multirow{2}{*}{$\begin{array}{l}\text { Relative MD area }\left(\mathrm{cm}^{2}\right) \\
\text { change per year }\end{array}$} & \multicolumn{2}{|c|}{$\begin{array}{c}\text { All women } \\
(\mathrm{N}=43810 ; \mathrm{BC} \text { cases }=563)\end{array}$} & \multicolumn{2}{|c|}{$\begin{array}{c}\text { Premenopausal women } \\
(\mathrm{N}=20718 ; \mathrm{BC} \text { cases }=200)\end{array}$} & \multicolumn{2}{|c|}{$\begin{array}{l}\text { Postmenopausal women } \\
(\mathrm{N}=23092 ; \mathrm{BC} \text { cases }=363)\end{array}$} \\
\hline & Person, years & HR $(95 \%$ CI)* & Person, years & HR $(95 \% \text { CI })^{*}$ & Person, years & HR $(95 \% \text { CI) })^{*}$ \\
\hline Decrease in MD† & 172537 & 1.00 (Referent) & 90289 & 1.00 (Referent) & 82247 & 1.00 (Referent) \\
\hline Stable MD‡ & 151618 & 1.01 (0.82 to 1.23$)$ & 83319 & 1.05 (0.76 to 1.47$)$ & 68298 & 1.00 (0.77 to 1.28$)$ \\
\hline Increase MD§ & 129116 & 0.98 (0.80 to 1.22$)$ & 62369 & 1.12 (0.77 to 1.64$)$ & 66747 & 0.95 (0.72 to 1.20$)$ \\
\hline
\end{tabular}

*Adjusted for age (continuous), BMI (continuous), and MD area (continuous) at baseline. $\mathrm{BC}=$ breast cancer; $\mathrm{BMI}=\mathrm{body}$ mass index; $\mathrm{CI}=\mathrm{confidence} \mathrm{interval;} \mathrm{HR}=\mathrm{haz}-$ ard ratio; $\mathrm{MD}=$ mammographic density.

†Defined as an annual decrease of relative MD area by more than $10 \%$.

‡Defined as no annual relative mammographic density change.

$\S$ Defined as an annual increase of relative MDC by more than $10 \%$.

mammograms from two or more examinations for each of the participants, and repeated and longitudinal measurement of MD after aligning images using the fully automated STRATUS tool (15).

The study had a number of limitations. Information on BC risk factors was based on a self-reported questionnaire and therefore is prone to information bias. However, a substantial differential misclassification is unlikely because women were not aware of their MD or the potential association between BC risk factors and MDC. Furthermore, answers were given before diagnosis. We lacked longitudinal information on established $\mathrm{BC}$ risk factors. All information on covariates was collected at baseline or at the date of the first mammogram. Repeated measures of BMI were only available for a subset of women $(n=7837)$. During the average follow-up of 5.4years, BMI changed very little, on average $0.02 \mathrm{~kg} / \mathrm{m}^{2} / \mathrm{y}$. We did not expect dramatic changes in most of the risk factors, including reproductive history, given the mean age of 53.7 years for the cohort members. Only approximately $3 \%$ of the participants used MHT, and it is therefore not likely that changes in use of MHT would substantially affect our findings. Another limitation of this study is that participants of the KARMA cohort were screening attendants and are highly educated and tend to have a healthier lifestyle than the participants of most studies. This may explain the weak and statistically nonsignificant association of BMI and postmenopausal BC risk.

Previous studies, which did not find any evidence of association between MDC and risk of BC, suggested that reductions in 
Table 4. HR of BC risk in relation to categories of baseline MD and change in MD area

\begin{tabular}{|c|c|c|c|c|}
\hline Baseline $\mathrm{MD}\left(\mathrm{cm}^{2}\right)$ & Decrease in MD* HR $(95 \% \mathrm{CI}) \dagger$ & Stable MD $\ddagger$ HR $(95 \%$ CI)† & Increase in MD§HR $(95 \% \mathrm{CI}) \dagger$ & $P_{\text {interaction }} \|$ \\
\hline All women & & & & .20 \\
\hline$<9.0$ & 1.00 (Referent) & 1.66 (0.96 to 2.86$)$ & 1.17 (0.75 to 1.83$)$ & \\
\hline $9.0-20.0$ & 2.29 (1.50 to 3.54$)$ & 1.67 (1.01 to 2.76$)$ & 1.94 (1.20 to 3.13$)$ & \\
\hline$>20$ & 2.61 (1.74 to 3.91$)$ & 2.70 (1.82 to 4.02$)$ & 2.91 (1.90 to 4.48$)$ & \\
\hline Premenopausal women & & & & .98 \\
\hline$<9.0$ & 1.00 (Referent) & 1.00 (0.10 to 9.96$)$ & $1.20(0.26$ to 5.38$)$ & \\
\hline $9.0-20.0$ & 3.37 (0.94 to 12.03$)$ & $2.80(0.70$ to 11.26$)$ & $3.50(0.94$ to 13.01$)$ & \\
\hline$>20$ & $4.27(1.31$ to 13.83$)$ & $4.83(1.50$ to 15.65$)$ & $5.02(1.51$ to 16.64$)$ & \\
\hline Postmenopausal women & & & & .21 \\
\hline$<9.0$ & 1.00 (Referent) & 1.68 (0.95 to 2.95$)$ & 1.15 (0.72 to 1.83$)$ & \\
\hline $9.0-20.0$ & 2.25 (1.41 to 3.60$)$ & $1.60(0.92$ to 2.74$)$ & 1.80 (1.06 to 3.05$)$ & \\
\hline$>20$ & 2.41 (1.53 to 3.79$)$ & 2.34 (1.50 to 3.64$)$ & 2.62 (1.60 to 4.31$)$ & \\
\hline
\end{tabular}

${ }^{*}$ Defined as an annual decrease of relative MD area by more than $10 \%$. BC = breast cancer; $\mathrm{BMI}=$ body mass index; $\mathrm{CI}=\mathrm{confidence}$ interval; $\mathrm{HR}=\mathrm{hazard}$ ratio; $\mathrm{MD}=$ mammographic density; MDC = mammographic density change. †Adjusted for age (continuous) and BMI (continuous) at baseline. $\neq$ Defined as no annual relative MDC

$\S$ Defined as an annual increase of relative MDC by more than $10 \%$. $\| P$ value from two-sided Wald test for interaction term.

density may occur at a young age, especially around menopause. Thus, perimenopausal age may be the critical period to investigate the association of MDC and risk of $\mathrm{BC}(10,12)$. However, these researchers could not investigate the association between MDC and risk of BC among premenopausal women, because BC screening programs in most countries start at the age of 50 years (10-12). One of the earlier small studies, composed of mostly premenopausal women, found a twofold increase in risk for women who persisted at high categories of density based on the Wolf density category (27). This is in agreement with our results showing that perimenopausal women (age 40-49years) who did not decrease in MD by more than $10 \%$ per year had a statistically nonsignificant higher risk of BC compared with perimenopausal women who decreased in MD.

We observed that, at fixed levels of baseline MD, the risk of $B C$ did not seem to be influenced by MDC. An explanation could be that baseline MD is a strong risk factor, primarily based on the cumulative exposure to female sex hormones during the premenopausal part of life, and is not influenced by the subsequent rate of density change. The vast majority of women experience involution, that is, the process by which the breast epithelial tissue is gradually converted to fatty tissue. Whether this conversion is seen at more or less than $10 \%$ per year is of lesser importance from a risk point of view compared with the baseline MD.

As a conclusion, we found no evidence on the association between MDC and risk of BC. Also, adding MDC to baseline MD did not seem to strengthen the association between baseline $\mathrm{MD}$ and risk of $\mathrm{BC}$ in our dataset. However, in line with previous studies, we observed a weak and statistically nonsignificant association between MDC and risk of BC among perimenopausal women (age 40-49years), which indicates that change in MD at a younger age might be of importance.

\section{Funding}

This work was supported by the Märit and Hans Rausing's Initiative Against Breast Cancer.

\section{Notes}

Affiliations of authors: Department of Medical Epidemiology and Biostatistics, Karolinska Institutet, Stockholm, Sweden (SA, ME, AS, RH, MG, KC, PH); Department of Radiology (RH) and Department of Oncology (PH), Södersjukhuset, Stockholm, Sweden.

The funder had no role in the study design, data collection, analyses and data interpretation, writing of the manuscript, or the decision to submit the manuscript for publication. The authors declare that they have no conflicts of interest.

Author contributions: SA participated in the study design, performed the statistical analyses and interpretation of the results with support from AS, and drafted the manuscript. ME, AS, RH, MG, KC, and PH participated in the study design, and interoperation of the results and helped draft the manuscript. All authors read and approved the final manuscript.

The authors thank all the participants in the KARMA study and personnel for this devoted work during data collection. They also acknowledge Jose Tapia for the efforts with data maintenance and handling.

\section{References}

1. McCormack VA, dos Santos Silva I. Breast density and parenchymal patterns as markers of breast cancer risk: a meta-analysis. Cancer Epidemiol Biomarkers Prev. 2006;15(6):1159-1169.

2. Vachon CM, van Gils CH, Sellers TA, et al. Mammographic density, breast cancer risk and risk prediction. Breast Cancer Res. 2007;9(6):217.

3. Boyd NF, Martin LJ, Bronskill M, Yaffe MJ, Duric N, Minkin S. Breast tissue composition and susceptibility to breast cancer. J Natl Cancer Inst. 2010; 102(16):1224-1237.

4. Boyd NF, Guo H, Martin LJ, et al. Mammographic density and the risk and detection of breast cancer. N Engl J Med. 2007;356(3):227-236.

5. Wolfe JN. Breast patterns as an index of risk for developing breast cancer. AJR Am J Roentgenol. 1976;126(6):1130-1137.

6. Boyd N, Martin L, Stone J, Little L, Minkin S, Yaffe M. A longitudinal study of the effects of menopause on mammographic features. Cancer Epidemiol Biomarkers Prev. 2002;11(10, pt 1):1048-1053.

7. Checka CM, Chun JE, Schnabel FR, Lee J, Toth H. The relationship of mammographic density and age: implications for breast cancer screening. AJR. 2012; 198(3):W292-W295.

8. Li T, Sun L, Miller N, et al. The association of measured breast tissue characteristics with mammographic density and other risk factors for breast cancer. Cancer Epidemiol Biomarkers Prev. 2005;14(2):343-349. 
9. Azam S, Sjölander A, Eriksson M, Gabrielson M, Czene K, Hall P. Determinants of mammographic density change. JNCI Cancer Spectrum, 3 (1), March 2019, pkz004, https://doi.org/10.1093/jncics/pkz004

10. Lokate M, Stellato RK, Veldhuis WB, Peeters $\mathrm{PH}$, van Gils $\mathrm{CH}$. Age-related changes in mammographic density and breast cancer risk. Am J Epidemiol. 2013;178(1):101-109.

11. Maskarinec G, Pagano I, Lurie G, Kolonel LN. A longitudinal investigation of mammographic density: the multiethnic cohort. Cancer Epidemiol Biomarkers Prev. 2006;15(4):732-739.

12. Vachon CM, Pankratz VS, Scott CG, Maloney SD, Ghosh K, Brandt KR. Longitudinal trends in mammographic percent density and breast cancer risk. Cancer Epidemiol Biomarkers Prev. 2007;16(5):921-928.

13. van Gils $\mathrm{CH}$, Hendriks $\mathrm{JH}$, Holland R, et al. Changes in mammographic breast density and concomitant changes in breast cancer risk. Eur J Cancer Prev. 1999;8(6):509-515.

14. Kerlikowske K, Ichikawa L, Miglioretti DL, et al. Longitudinal measurement of clinical mammographic breast density to improve estimation of breast cancer risk. J Natl Cancer Inst. 2007;99(5):386-395.

15. Eriksson M, Li J, Leifland K, Czene K, Hall P. A comprehensive tool for measuring mammographic density changes over time. Breast Cancer Res Treat. 2018 169(2):371-379.

16. Gabrielson M, Eriksson M, Hammarstrom M, et al. Cohort profile: the Karolinska mammography project for risk prediction of breast cancer (KARMA). Int J Epidemiol. 2017;46(6):1740-1741g.

17. Rauh C, Hack CC, Haberle L, et al. Percent mammographic density and dense area as risk factors for breast cancer. Geburtshilfe Frauenheilkd. 2012;72(8): 727-733.

18. D'Orsi C. J., Bassett L. W., Berg W. A., et al. Breast imaging reporting and data system: ACR BI-RADS - breast imaging atlas. Am Coll Radiol. 2003;4(3):871-880.
19. Cuzick J, Warwick J, Pinney E, et al. Tamoxifen-induced reduction in mammographic density and breast cancer risk reduction: a nested case-control study. J Natl Cancer Inst. 2011;103(9):744-752.

20. Sandberg ME, Li J, Hall P, et al. Change of mammographic density predicts the risk of contralateral breast cancer-a case-control study. Breast Cancer Res. 2013;15(4):R57

21. Beral V, Bull D, Doll R, Peto R, Reeves G; Collaborative Group on Hormonal Factors in Breast Cancer. Familial breast cancer: collaborative reanalysis of individual data from 52 epidemiological studies including 58,209 women with breast cancer and 101,986 women without the disease. Lancet (London, England). 2001;358(9291):1389-1399.

22. Beral V. Breast cancer and hormone-replacement therapy in the Million Women Study. Lancet (London, England). 2003;362(9382):419-427.

23. Lambe M, Hsieh CC, Chan HW, Ekbom A, Trichopoulos D, Adami HO. Parity, age at first and last birth, and risk of breast cancer: a population-based study in Sweden. Breast Cancer Res Tr. 1996;38(3):305-311.

24. Schoemaker MJ, Nichols HB, Wright LB, et al. Association of body mass index and age with subsequent breast cancer risk in premenopausal women. JAMA Oncol. 2018;4(11):e181771.

25. van den Brandt PA, Spiegelman D, Yaun SS, et al. Pooled analysis of prospective cohort studies on height, weight, and breast cancer risk. Am J Epidemiol. 2000;152(6):514-527.

26. Duffy SW, Morrish OWE, Allgood PC, et al. Mammographic density and breast cancer risk in breast screening assessment cases and women with a family history of breast cancer. Eur J Cancer (Oxford, England: 1990). 2018;88: 48-56.

27. Salminen TM, Saarenmaa IE, Heikkila MM, Hakama M. Risk of breast cancer and changes in mammographic parenchymal patterns over time. Acta Oncol (Stockholm, Sweden). 1998;37(6):547-551. 